\title{
Using in-situ Adsorption Dilatometry for Assessment of Micropore Size Distribution in Monolithic Carbons
}

Piotr Kowalczyk ${ }^{* 1}$, Christian Balzer ${ }^{2}$, Gudrun Reichenauer ${ }^{2}$, Artur P. Terzyk ${ }^{3}$, Piotr A. Gauden ${ }^{3}$ and Alexander V. Neimark ${ }^{4}$

${ }^{1}$ School of Engineering and Information Technology, Murdoch University, Murdoch 6150 Western Australia, Australia

${ }^{2}$ Bavarian Center for Applied Energy Research, Magdalene-Schoch-Str. 3, 97074 Wuerzburg, Germany

${ }^{3}$ Faculty of Chemistry, Physicochemistry of Carbon Materials Research Group, Nicolaus Copernicus University in Toruń, Gagarin St. 7, 87-100 Toruń, Poland

${ }^{4}$ Department of Chemical and Biochemical Engineering, Rutgers, The State University of New Jersey, 98 Brett Road, Piscataway, New Jersey 08854-8058, United States

Corresponding author. Email:P.Kowalczyk@murdoch.edu.au (Piotr Kowalczyk) 


\begin{abstract}
We demonstrate that in-situ adsorption dilatometry provides a new opportunity for structural characterization of microporous carbons. We present experimental results for $\mathrm{CO}_{2}$ adsorption at $293 \mathrm{~K}$ and in-situ deformation obtained by dilatometry on a synthetic monolithic carbon sample. The carbon deformation in the course of adsorption is non-monotonic: the strain isotherm shows the sample contraction at low adsorption followed by progressive expansion. To evaluate structural and mechanical properties of the sample from the experimental adsorption and strain isotherms, a kernel of theoretical adsorption isotherms is obtained with the grand canonical Monte Carlo simulation of $\mathrm{CO}_{2}$ adsorption in a series of carbon micropores ranging from 0.22 to $2.0 \mathrm{~nm}$. The respective kernel of adsorption stress isotherms is constructed using the thermodynamic model of adsorption stress. The pore volume and surface area distributions were calculated independently from a) the experimental excess adsorption isotherm by deconvoluting the generalized adsorption equation and b) the experimental strain isotherm by using the kernel of adsorption stress isotherms. The proposed method of determining the pore size distribution from the strain isotherm validates the thermodynamic model of adsorption stress in micropores and provides additional information about the sample material with respect to mechanical properties of the microporous matrix.
\end{abstract}




\section{Introduction}

Structural characterization of disordered and heterogeneous carbonaceous materials (e.g. activated carbons, activated carbon fibers, carbon molecular sieves, carbon xerogels/aerogels and coals) is one of the fundamental steps in understanding and improving their respective performance in technical applications including separations, sequestrations, gas storage, supercapacitors and batteries, adsorption/desorption heat pumps, catalysis, and many others [1-7]. Various experimental and theoretical studies conducted on this subject concluded that disordered carbonaceous materials could be described as nano-scale pores of various sizes embedded into a disordered carbon matrix [8-16]. For most carbonaceous materials the majority of relevant pore volume is related to micropores, i.e. pores smaller than $2 \mathrm{~nm}$, where the solid-fluid interactions are significantly enhanced compared to larger pores [17]. Micropores in turn are further subdivided into ultramicropores (pores smaller than $0.7 \mathrm{~nm}$ ) and supermicropores (pore sizes between 0.7 to $2 \mathrm{~nm}$ ) [18]. Due to their high degree of disorder and the associated broad pore size distributions the analysis of technical relevant carbon structures is often a complex task, which still is an object of academic and technical research $[19,20]$.

Gas adsorption experiments, e.g. $\mathrm{N}_{2}$ at $77 \mathrm{~K}$, Ar at $87 \mathrm{~K}$ or $\mathrm{CO}_{2}$ at $273 \mathrm{~K}$, are commonly used to determine structural properties of microporous carbons, such as surface area and pore size distribution. The current state of the art for the analysis of adsorption isotherms is based on the numerical solution of the general adsorption equation, which is based on a set of theoretical adsorption isotherms (a so-called kernel) for discrete pore sizes [21-24]. The result of this process is the pore size distribution of the material. Most kernels implemented in nowadays commercial software tools were generated with the nonlocal [25-27] and more recently quenched solid density functional theory [28] (NLDFT and QSDFT, respectively); in rare cases the more extensive technique of grand canonical Monte Carlo (GCMC) simulation was applied [29-32]. However, regardless of the kernel's derivation the solution of the general adsorption equation itself is an ill-posed problem from the mathematical point of view, i.e. the resulting pore size distributions are not entirely unambiguous $[33,34]$. Therefore, alternative ways to validate an obtained pore size distribution are desirable.

Here we perform a quantitative analysis of adsorption-induced deformation as a complementary approach to access the micropore structure of carbons. The effect of 
sorption-induced deformation for microporous carbons is known since the 1920s [35] and related to the structural change of adsorbents in the course of adsorption process. Experimentally observed deformations during gas adsorption on monolithic carbonaceous materials are usually smaller than $1 \mathrm{vol} \%$ and therefore this effect is almost always neglected [36-38]. However, within the last decade several theoretical studies based on DFT and GCMC were conducted in order to understand its microscopic origin [39-45]. These studies identified the packing of the adsorbed molecules inside slit-shaped carbon micropores as a key factor for the mechanical response of a micropore to gas adsorption: if the width of a slit-shaped micropore is commensurate to the molecular diameter of the adsorbed species, the packing of the adsorbed molecules is very dense and the pore expands. On the contrary, for pores, whose size is incommensurate to the molecular diameter of the adsorbed molecule, the packing will be less dense and the attractive potentials of the opposing walls cause the micropore to contract. This geometrical effect makes the analysis of sorptioninduced deformation a promising approach for the evaluation of pore size distributions.

For this work we recorded a $\mathrm{CO}_{2}$ adsorption isotherm at $293 \mathrm{~K}$ on a synthetic microporous carbon prepared in our lab complemented by in-situ measurement of the sample's adsorption-induced deformation via dilatometry. Two independent theoretical methods based on the GCMC simulation model of $\mathrm{CO}_{2}$ adsorption in carbon pores were used in order to compute structural parameters of the sample investigated. Firstly, we followed the common approach to solve the generalized adsorption equation, which convolutes the kernel of theoretical isotherms with the sought pore size distribution to describe the experimental $\mathrm{CO}_{2}$ excess adsorption isotherm. The theoretical kernel of excess isotherms was constructed with rotationalbias GCMC simulation of $\mathrm{CO}_{2}$ adsorption in carbon pores ranging from 0.22 to $2.0 \mathrm{~nm}$. Secondly, we calculated the kernel of adsorption stress isotherms using the thermodynamic model of adsorption-induced deformation of microporous materials and determined the pore size distribution by fitting the experimental strain isotherm with this kernel. The main question to be addressed is whether the structural parameters, i.e. the distribution of micropore volume and surface area as well as the total micropore surface area and volume, evaluated from the $\mathrm{CO}_{2}$ excess adsorption isotherm are consistent with those computed from the in-situ deformation data. The positive answer opens up a new opportunity of the independent evaluation of 
micropore structure. Furthermore, we extrapolated both $\mathrm{CO}_{2}$ excess adsorption and strain isotherm up to saturation, which was not accessible to our experiment limited to the atmospheric pressure.

\section{Material, Experimental Techniques and Simulation}

\subsection{Sol-gel based synthetic carbon xerogels}

The sample investigated was a monolithic rod of synthetic amorphous carbon xerogel derived by pyrolysis at $800{ }^{\circ} \mathrm{C}$ under argon atmosphere from an organic xerogel precursor. The organic precursor was synthesized via a sol-gel process based on the approach proposed by Pekala and co-workers [46] but modified with respect to educt ratios, gelation/aging period and drying [47]. The molar ratio of resorcinol to catalyst was set to 5000, the mass ratio of resorcinol and formaldehyde to the mass of the total starting solution was $30 \%$ and the gelation/aging period was $24 \mathrm{~h}$. The length of the final sample rod was $L_{0}=73.4 \mathrm{~mm}$, its diameter $3.7 \mathrm{~mm}$. The macroscopic (apparent) density of the $\operatorname{rod} \rho_{m}=(0.292 \pm 0.011) \mathrm{g} / \mathrm{cm}^{3}$ was determined after degassing the sample for $4 \mathrm{~d}$ at $300 \mathrm{~K}$ and a pressure below $10^{-2} \mathrm{mbar}$. As shown in details in ref. 48 this type of carbon material consists of microporous particles of approximately spherical geometry, forming a disordered three-dimensional network. A scanning electron microscopy (SEM) image of the sample investigated is shown in

Figure 1a. From this image the average particle diameter of the sample $d_{S E M}$ was estimated to be in the range of 300 to $500 \mathrm{~nm}$. 

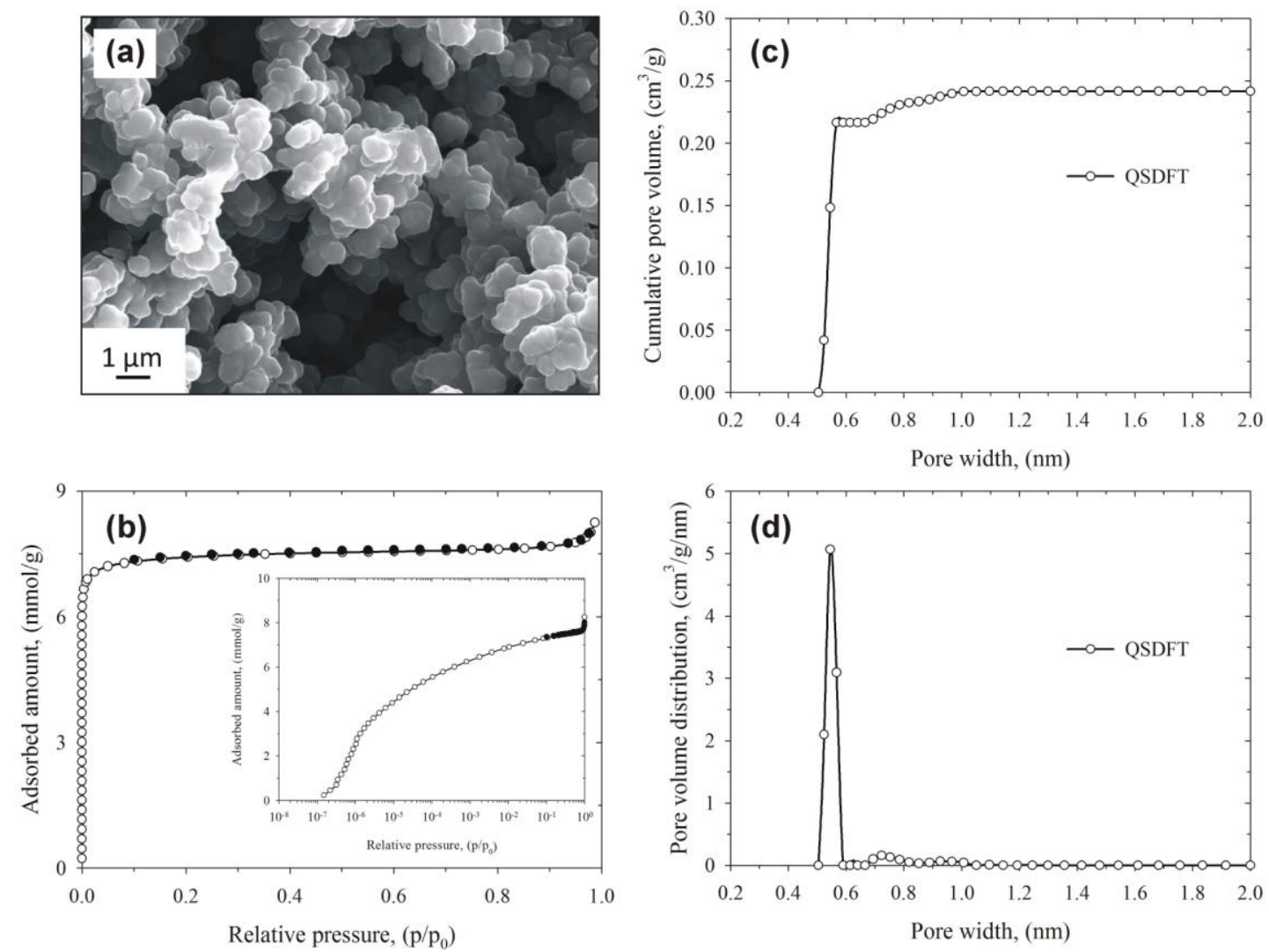

Figure 1. Panel (a) shows the SEM image of the studied carbon xerogel. $\mathrm{N}_{2}$ adsorption-desorption isotherm measured on this sample at $77 \mathrm{~K}$ is presented in panel (b). QSDFT cumulative and differential pore volume distributions computed from $\mathrm{N}_{2}$ adsorption isotherm are shown in panel (c) and (d), respectively.

Furthermore the sample's structure was investigated by $\mathrm{N}_{2}$ sorption at $77 \mathrm{~K}$. The respective sorption isotherm is shown in Figure 1b; its Langmuirian shape (isotherm type I following to International Union of Pure and Applied Chemistry $[49,50])$ is typical for carbonaceous materials with micropores. The evaluation of the nitrogen sorption data according to the t-plot method [51] using the reference isotherm suggested by Magee [52] yields a specific particle surface area of $S_{\text {ext }}=(11$ $\pm 1) \mathrm{m}^{2} / \mathrm{g}$ and a specific micropore volume of $V_{\text {mic }}=(0.25 \pm 0.01) \mathrm{cm}^{3} / \mathrm{g}$. With the density of the nonporous carbon backbone $\rho_{c}=(2.06 \pm 0.06) \mathrm{g} / \mathrm{cm}^{3}$ from literature [53] we calculated the density of the purely microporous primary particles $\rho_{\text {part }}=$ $1 /\left(V_{\text {mic }}+1 / \rho_{c}\right)=(1.36 \pm 0.04) \mathrm{g} / \mathrm{cm}^{3}$. To validate the result for $\rho_{\text {part }}$ we assume spherical geometry for the primary particles and determine an average particle 
diameter $d_{\text {part }}=6 /\left(\rho_{\text {part }} \cdot S_{\text {ext }}\right)=(396 \pm 38) \mathrm{nm}$, which is in good agreement with $d_{S E M}$. The results of the sample characterization are summarized in Table 1.

\begin{tabular}{|c|c|c|c|c|c|}
\hline$\rho_{m}\left(\mathrm{~g} / \mathrm{cm}^{3}\right)$ & $\rho_{\text {part }}\left(\mathrm{g} / \mathrm{cm}^{3}\right)$ & $V_{\text {mic }}\left(\mathrm{cm}^{3} / \mathrm{g}\right)$ & $S_{\text {ext }}\left(\mathrm{m}^{2} / \mathrm{g}\right)$ & $d_{S E M}(\mathrm{~nm})$ & $d_{\text {part }}(\mathrm{nm})$ \\
\hline $0.292 \pm 0.011$ & $1.36 \pm 0.04$ & $0.25 \pm 0.01$ & $11 \pm 1$ & $300-500$ & $396 \pm 38$ \\
\hline
\end{tabular}

Table 1. Results of the sample characterization: $\rho_{m}$ is the macroscopic (apparent) density, $\rho_{\text {part }}$ the particle density, $V_{\text {mic }}$ the specific micropore volume, $S_{\text {ext }}$ the specific surface area, $d_{S E M}$ the particle diameter as seen by SEM, and $d_{\text {part }}$ the particle diameter calculated from structural properties.

The microporosity of the sample was further investigated by NLDFT and QSDFT analysis of the $\mathrm{N}_{2}$ sorption isotherm according to refs. [10,28], respectively. Classical NLDFT and QSDFT models generate similar pore volume distributions, thus only QSDFT results are shown in Figure 1c-d. The overall cumulative micropore volumes of $V_{\text {cum }}(\mathrm{NLDFT})=0.255 \mathrm{~cm}^{3} / \mathrm{g}$ and $V_{\text {cum }}(\mathrm{QSDFT})=0.249 \mathrm{~cm}^{3} / \mathrm{g}$ are well in line with $V_{\text {mic }}$ determined from the t-plot method. According to DFT analysis the major part of the microporosity of the sample investigated is in the range of 0.5 to $0.6 \mathrm{~nm}$ (see Figure 1c-d). The total specific micropore areas found by NLDFT and QSDFT are $857 \mathrm{~m}^{2} / \mathrm{g}$ and $854 \mathrm{~m}^{2} / \mathrm{g}$, respectively.

\subsection{Sorption measurement with in-situ dilatometry}

Simultaneous measurements of $\mathrm{CO}_{2}$ adsorption and sample deformation were performed by a commercial volumetric sorption instrument (ASAP 2020, Micromeritics, Norcross GA, USA) equipped with a self-designed dilatometer. A scheme of the dilatometer is shown in Figure 2. Its main parts are a customized sample holder and a length sensor (LVDT, Macro Sensors, Pennsauken, NJ, USA). The lower part of the sample holder containing the sample is placed in the liquid bath used to maintain constant temperature, while the upper part mounted with the length sensor is attached to the volumetric sorption instrument. The length sensor consists of two parts: a cylindrical metal core inside the sample holder and an electrical coil arrangement on the outer side of the sample holder. The metal core is connected to the 
sample by a push rod made of glass, which transfers deformations of the sample onto the metal core. Displacements of the metal core in turn result in changes of electrical inductivities within the coil arrangement allowing measurements of the sample deformation. The overall setup simultaneously determines the adsorption isotherm, i.e. the amount of gas adsorbed as a function of the relative gas pressure $p / p_{0}$, and the corresponding change of the sample length $\Delta L$. This setup was successfully used for studies of sorption-induced deformation of micro- and mesoporous materials $[37,38,54]$. Similar setups were previously described in refs $[55,56]$. The resolution of the dilatometric setup is $\pm 0.2 \mu \mathrm{m}$ resulting in an accuracy for the linear strain of the sample $\Delta L / L_{0}$ of approximately $\pm 310^{-6}$ for the carbon sample investigated. For the measurement presented in this work the liquid bath was water at $20.0{ }^{\circ} \mathrm{C}$ regulated by a liquid thermostat with an external platinum temperature sensor (accuracy $\pm 0.2 \mathrm{~K}$ ). The vapor saturation pressure corresponding to the bath temperature is $p_{0}=(5.729 \pm$ 0.027) $\mathrm{MPa}$ [57], resulting in a relative error for the relative pressure $p / p_{0}$ of less than $1 \%$. Since the volumetric sorption instrument is limited to gas pressures $p<0.1 \mathrm{MPa}$, only the relative pressure range below 0.02 was accessible to the experiment. Prior to the measurement the sample was degassed within the sample holder attached to the analysis port of the sorption instrument for $3 \mathrm{~h}$ at $300^{\circ} \mathrm{C}$ and a gas pressure $<10^{-}$ ${ }^{3}$ mbar. This way the sample was not exposed to ambient atmosphere between degassing and measurement. 


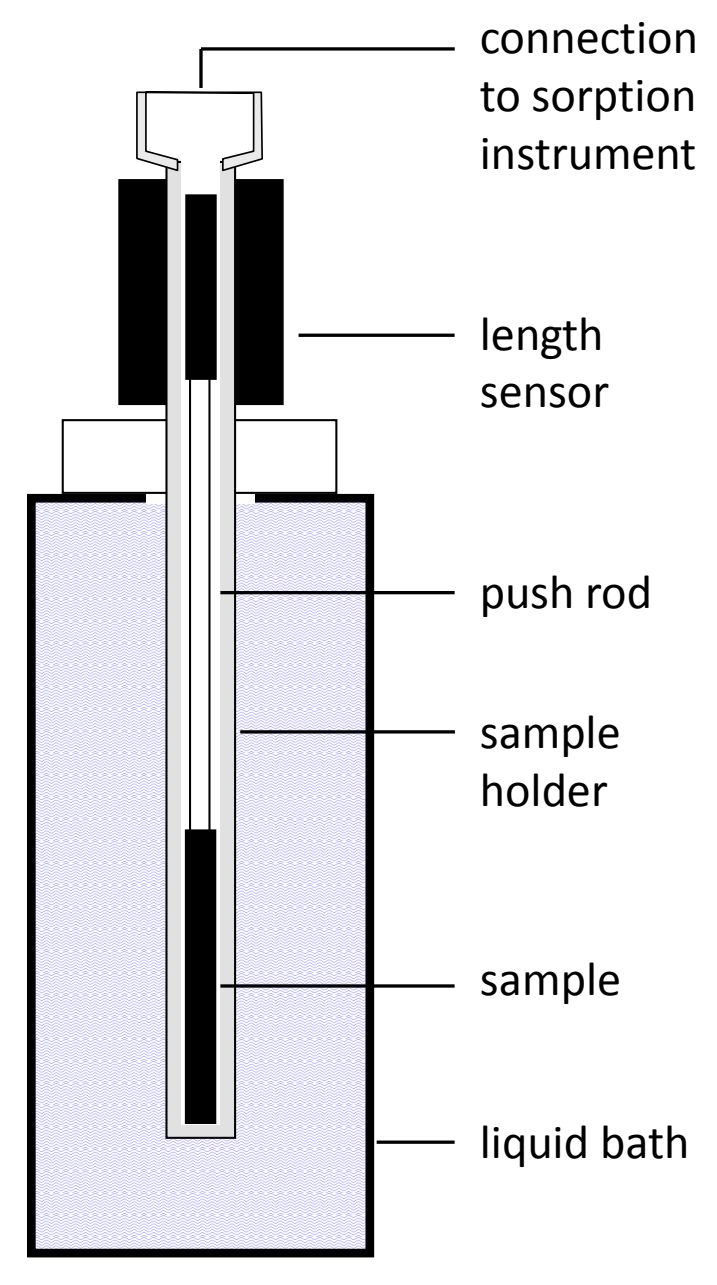

Figure 2. Scheme of the dilatometer.

\subsection{Molecular Models and Simulation Details}

We used a three-site rigid linear model of $\mathrm{CO}_{2}$ molecules [58] for $\mathrm{MC}$ simulation of adsorption isotherms. The values of the electrostatic point charges and the $(12,6)$ Lennard-Jones dispersion parameters for $\mathrm{CO}_{2}$ are given in refs. [58,59]. The applied force field was previously verified against available experimental data [58]. Additionally, we compared the theoretical equation of state for $\mathrm{CO}_{2}$ at $293 \mathrm{~K}$ with experimental measurements (see Figure $1 \mathrm{~S}$ in supporting information). Micropores were modeled as uncharged graphitic slit-shaped pores of width $H$, where $H=H_{\text {geom }}-0.34 \mathrm{~nm}$ denotes pore width accessible to $\mathrm{CO}_{2}$ molecules, and $H_{\text {geom }}$ is the geometrical pore width measured as the distance between planes through the first atomic layer of carbon nuclei of opposing walls. The dispersion interactions between 
$\mathrm{CO}_{2}$ molecules and graphitic pore walls were computed from the well-known 10-4-3 Steele potential [60]. The cross-terms parameters for dispersion interactions were evaluated with Lorentz-Berthelot combining rule [61].

Adsorption isotherms were computed from the rotational-bias grand canonical Monte Carlo method implemented by Kowalczyk and co-workers [62]. The setup for GCMC simulation of $\mathrm{CO}_{2}$ adsorption in slit-shaped pore geometry represented cubic simulation box of size $L_{x} \quad L_{y} \quad H$ with $L_{x}=L_{y}=4 \mathrm{~nm}$ and periodic boundary conditions and minimum image convention for computing $\mathrm{CO}_{2}-\mathrm{CO}_{2}$ interactions in $x$ and $y$-directions [43]. The Monte Carlo trial moves (insertion/deletion, and translational/rotation of $\mathrm{CO}_{2}$ molecules) were taken with 1:1:1 proportionality. We used 10 trial orientations to bias insertion and deletion movies. GCMC simulations utilized $510^{7}$ configurations. The first $2 \quad 10^{7}$ configurations were discarded to secure equilibration. We generated 62 adsorption isotherms of $\mathrm{CO}_{2}$ at $293 \mathrm{~K}$ and relative pressures, $p / p_{0}$, from $910^{-8}$ to 0.99 . All simulated isotherms consisted of 56 points and covered the range of micropore sizes accessible to $\mathrm{CO}_{2}$ molecules, i.e. slitshaped carbon pore width ranging from 0.22 to $2.0 \mathrm{~nm}$.

\subsection{Microporo-Elastic Properties}

\subsection{1 $\mathrm{CO}_{2}$ excess adsorption: Structural and Adsorptive Properties}

The generalized adsorption equation (GAE) was solved with the kernel of theoretical $\mathrm{CO}_{2}$ excess adsorption isotherms simulated by rotational-bias GCMC method at $293 \mathrm{~K}$. Noteworthy, that while the standard methods of pore size analysis for low temperature $\mathrm{N}_{2}$ and $\mathrm{Ar}$ adsorption are based on theoretical absolute adsorption isotherm, in the case of $\mathrm{CO}_{2}$ adsorption at ambient conditions, the use of excess adsorption isotherms is essential due to the high vapor density. The solution was then used to compute the pore surface area distribution (PSD) from the experimental $\mathrm{CO}_{2}$ excess adsorption isotherm [19]:

$$
N_{\exp }(p)=\int_{H_{\min }}^{H_{\max }} N_{G C M C}(p, H) f_{s}(H) d H \quad \text { subject to } \quad f_{s}(H) \geq 0
$$


Here, $H_{\min }$ and $H_{\max }$ are the minimum and maximum pore widths within the kernel, $N_{\text {exp }}(p)$ is the experimental $\mathrm{CO}_{2}$ excess adsorption isotherm measured at $293 \mathrm{~K}$, $N_{G C M C}(p, H)$ is the kernel that represents the set of theoretical $\mathrm{CO}_{2}$ isotherms with excess quantity adsorbed per square meter, and $f_{s}(H)$ is the differential PSD function, which represents the surface area of pores of width $H$.

Theoretical $\mathrm{CO}_{2}$ excess adsorption isotherms in rigid slit-shaped carbon pores are computed from the following expression [61]:

$$
N_{G C M C}(p, H)=\frac{\langle N\rangle}{V}-\rho_{b}(p)
$$

where $\rho_{b}(p)$ is the bulk gas density of $\mathrm{CO}_{2}$ at given pressure $p$ at $293 \mathrm{~K}$ (see Figure $1 \mathrm{~S}$ in supporting information), $\langle N\rangle$ denotes the GCMC ensemble average number of $\mathrm{CO}_{2}$ molecules in the pore of accessible volume $V$. For slit-shaped pore geometry, the accessible volume of the pore is $V=L_{x} \cdot L_{y} \cdot H$.

The pore volume distribution (PVD) is computed from the PSD, $f_{s}(H)$, using the following relation:

$f_{v}(H)=(1 / 2) \cdot f_{s}(H) \cdot H$

The solution of the GAE is obtained using the discrete first and second order Tikhonov regularization method with the non-negative least-squares algorithm (see Kowalczyk et al. [3] for other details).

\subsection{2 $\mathrm{CO}_{2}$ in-situ deformation: Structural and Elastic Properties}

To describe adsorption-induced deformation we invoke the adsorption stress model proposed in ref. [39]. In case of the carbon xerogel investigated, micropore filling takes place inside the primary particles shown in Figure 1a. Since the particles composed of disordered assemblies of carbon microcrystallites, whose interspaces form the micropores, are isotropic and randomly oriented, the adsorption-induced deformation is also isotropic on the level of individual particles as well as on the level 
of the overall unconstrained particle network. Hence, the macroscopic length change of the carbon rod as seen by in-situ dilatometry is directly related to the isotropic volumetric deformation of the microporous particles. The volumetric strain $\varepsilon=\Delta V / V_{0}$ of the primary particles can be expressed by the experimentally determined linear strain $\Delta L / L_{0}$ by $\varepsilon=3 \Delta L / L_{0}$, if $\varepsilon<<1$. $\varepsilon$ in turn can be related to the effective adsorption stress $\bar{\sigma}_{a}$ inside the particle, which is represented by the convolution of the adsorption stress $\sigma_{a}(H, p)$ in the micropore of width $H$ with the PVD function $f_{v}(H)$, as follows [45]:

$$
\begin{aligned}
& \varepsilon=\frac{1}{K}\left[\bar{\sigma}_{a}-p\right] \\
& \bar{\sigma}_{a}=\frac{1}{V_{\text {part }}} \cdot \int \sigma_{a}(H, p) \cdot f_{v}(H) d H
\end{aligned}
$$

Here $K$ denotes the bulk modulus of the particle, $V_{\text {part }}=1 / \rho_{\text {part }}$ the specific volume of the primary particle and $f_{v}(H) d H$ is the specific micropore volume for micropores of width $(H, H+d H)$. Notably, within this model the bulk modulus of the primary particle does not change during the filling of micropores.

The adsorption stress $\sigma_{a}(H, p)$ in a slit-shaped micropore of width can be computed from the general thermodynamic relations $[39,45]$ :

$$
\begin{aligned}
& \sigma_{a}(H, p)=-\frac{\partial \Omega_{p}(H, p)}{\partial H} \\
& \Omega_{p}(\mu)=\Omega_{p}\left(\mu_{r}\right)-\int_{\mu_{r}}^{\mu} N d \mu \\
& \Omega_{p}\left(\mu_{r}\right)=-k_{B} N\left(\mu_{r}\right) T
\end{aligned}
$$


Here, $\Omega_{p}$ is the grand thermodynamic potential of the pore, $N$ the amount of adsorbed molecules, $k_{B}$ the Boltzmann constant, $T$ the temperature and $\mu$ and $\mu_{r}$ are the chemical potential and reference chemical potential, respectively. The successive substitution algorithm developed by Kowalczyk and co-workers [20] was used for solution of Equations 4-8.

\section{Results and Discussion}

\subsection{Simulation results}

Figure 3 displays theoretical $\mathrm{CO}_{2}$ absolute adsorption isotherms simulated from rotational-bias $\mathrm{GCMC}$ at $293 \mathrm{~K}$ for selected pore sizes. We notice that $\mathrm{CO}_{2}$ is strongly adsorbed in carbon ultramicropores with pore size $<0.7 \mathrm{~nm}$. The density of adsorbed $\mathrm{CO}_{2}$ in $0.28 \mathrm{~nm}$ reaches $30 \mathrm{mmol} / \mathrm{cm}^{3}$ and the adsorption stress approaches $\sim 2.9 \mathrm{GPa}$ at the saturation pressure of $5.71 \mathrm{MPa}$ (see Figs. 3-4). At $293 \mathrm{~K}$ this density corresponds to a $\mathrm{CO}_{2}$ bulk pressure of $0.295 \mathrm{GPa}$ [57]. The reason for the big difference between adsorption stress and bulk pressure is that $\mathrm{CO}_{2}$ molecules assemble as a quasi-two-dimensional solid inside the $0.28 \mathrm{~nm}$ ultramicropore (see $1 \mathrm{st}$ peak in Figure 4b), while $\mathrm{CO}_{2}$ in the bulk phase is a liquid. This comparison illustrates that the thermodynamic state of $\mathrm{CO}_{2}$ in ultramicropores cannot be achieved by simply compressing bulk $\mathrm{CO}_{2}$, but requires the confining geometry of micropores. $\mathrm{CO}_{2}$ adsorption in supermicropores starts at higher relative pressures $\sim 5 \cdot 10^{-2}$ and the density of adsorbed $\mathrm{CO}_{2}$ in supermicropores at saturation is lower than the density of saturated bulk $\mathrm{CO}_{2}$ liquid $\left(\sim 22.5 \mathrm{mmol} / \mathrm{cm}^{3}\right)$. These results indicate a sharp drop in the strength of surface forces and confining effects as the pore size increases. 


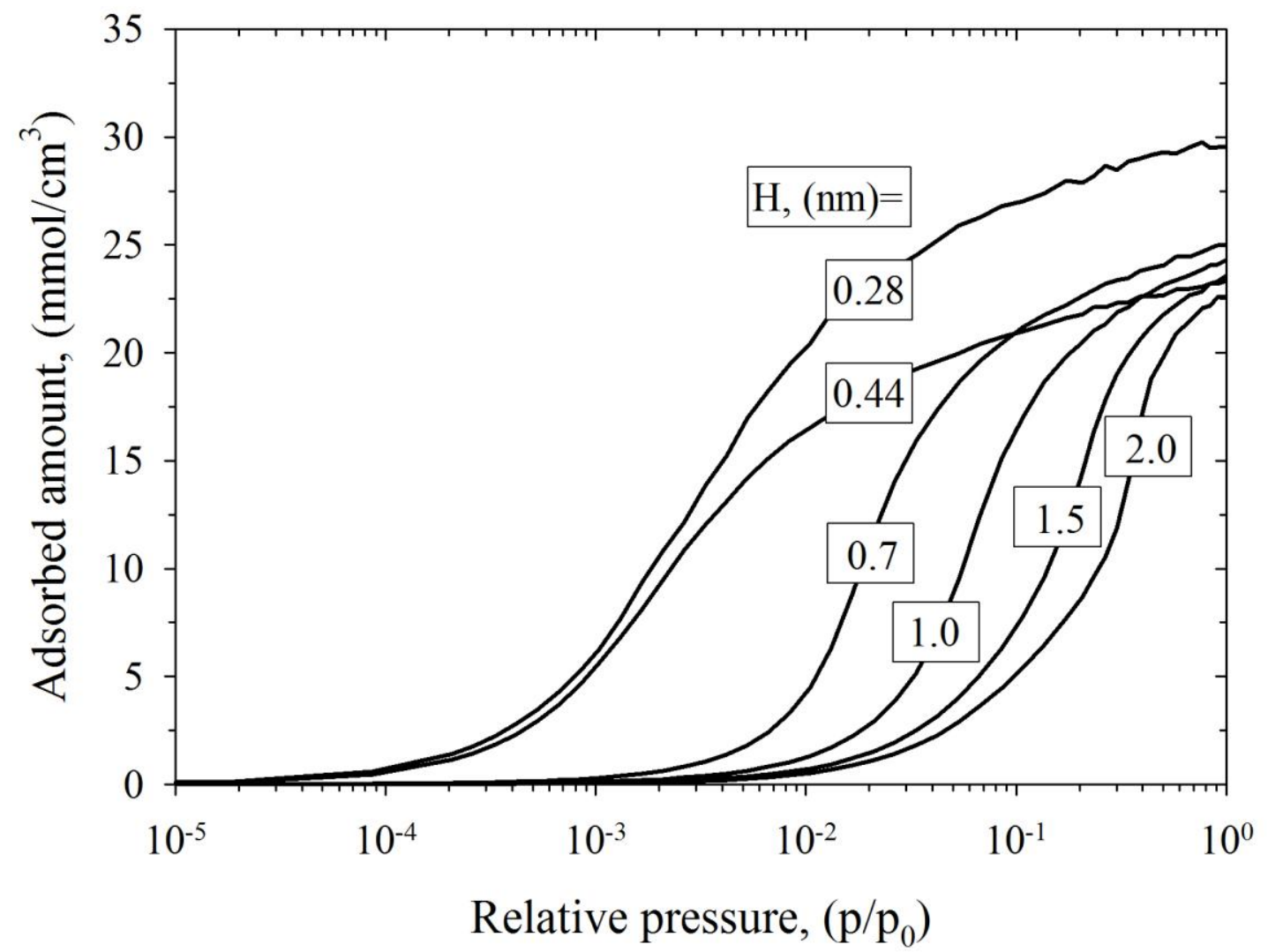

Figure 3. $\mathrm{CO}_{2}$ absolute adsorption isotherms simulated from rotational-bias GCMC for selected slit-shaped pore widths: $0.28,0.44,0.7,1.0,1.5$ and $2.0 \mathrm{~nm}$ at $293 \mathrm{~K}$.

Figure 4 shows the computed adsorption stress $\sigma_{a}$ as a function of micropore width and relative gas pressure. Our results correspond roughly to the oscillating behavior of adsorption stress with respect to pore width often reported for the adsorption of spherical molecules, see e.g. ref. 63. However, due to the linear geometry of the $\mathrm{CO}_{2}$ molecule the molecular packing in our model (and therefore also the adsorption stress) becomes more complex than for spherical molecules. The computed adsorption stress has its maximum in the smallest ultramicropores because of the enhanced surface forces. In such narrow ultramicropores, the adsorbed $\mathrm{CO}_{2}$ molecules are tightly packed and compressed into a defected two-dimensional quasisolid hexagonal layer (see 1st peak in Figure 4b). The highest value of the adsorption stress of $2.84 \mathrm{GPa}$ is computed for a $0.28 \mathrm{~nm}$ ultramicropore at $p / p_{0}=0.99$. For increasing pore size the adsorption stress is sharply decreasing because of the imperfect packing of $\mathrm{CO}_{2}$ molecules in slit-shaped carbon ultramicropores. The 
lowest value of the adsorption stress of $-0.34 \mathrm{GPa}$ is found for a $0.44 \mathrm{~nm}$ ultramicropore at $p / p_{0}=0.45$. Here, adsorbed $\mathrm{CO}_{2}$ molecules have enough rotational degrees of freedom to tilt inside the pore (see 3rd peak in Figure $4 \mathrm{~b}$ ) facilitating the generation of empty spaces. Other peaks corresponding to positive adsorption stress induced by adsorbed $\mathrm{CO}_{2}$ are found around 0.56 and $0.74 \mathrm{~nm}$, respectively. However, their intensities are significantly reduced compared to the first peak in agreement with computed $\mathrm{CO}_{2}$ pore densities in ultramicropores and supermicropores (see Figure 3). The maximal adsorption stress in 0.56 and $0.75 \mathrm{~nm}$ ultramicropores is only 0.2 and $0.06 \mathrm{GPa}$ at $p / p_{0}=0.99$, respectively. This strong damping of adsorption stress for increasing pore width can be attributed to the rather elevated temperature in our simulation as was demonstrated in refs. [43,63]. Consequently, we conclude that ultramicropores of pore widths around $0.3 \mathrm{~nm}$ have the greatest impact on the elastic deformation of heterogonous carbonaceous materials. 


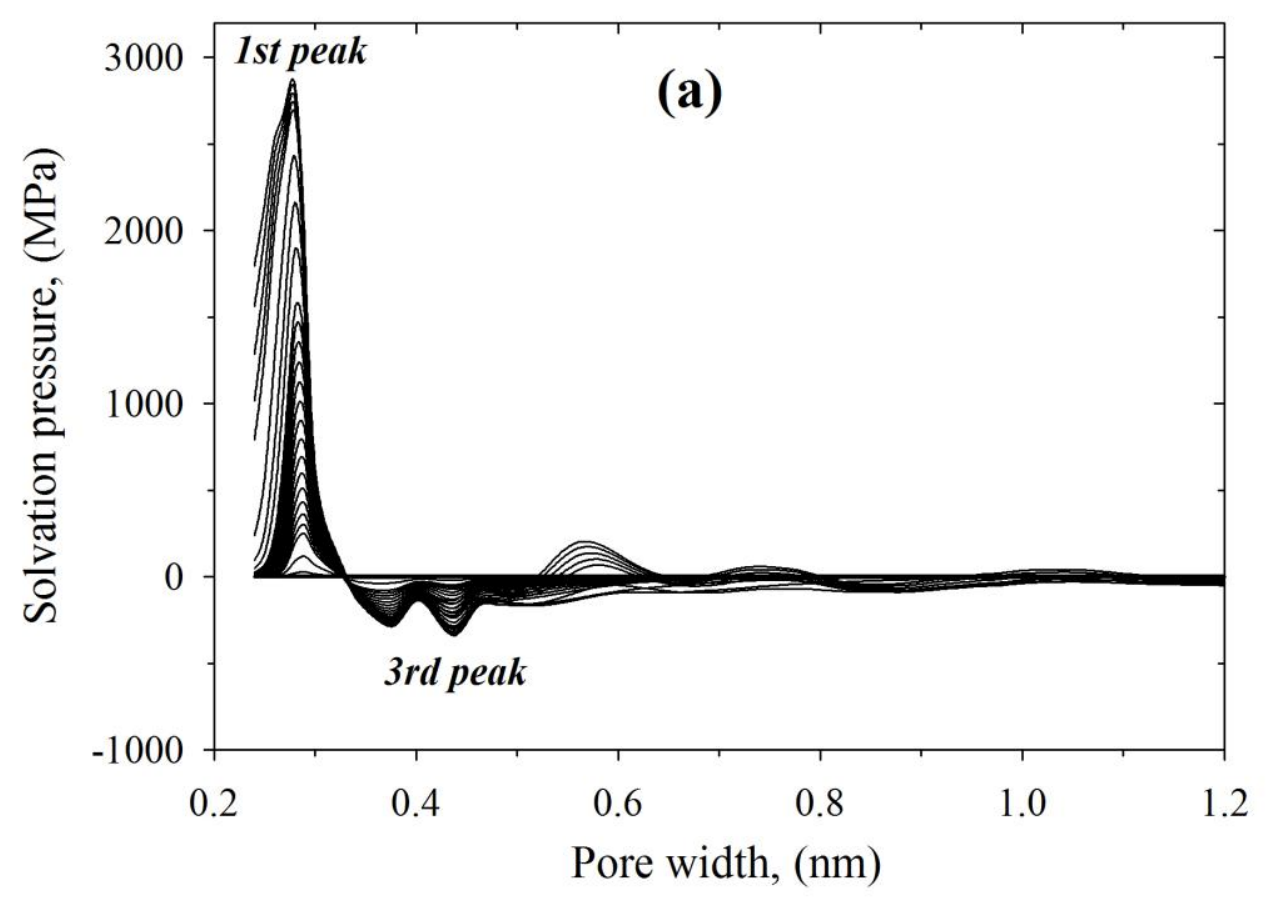

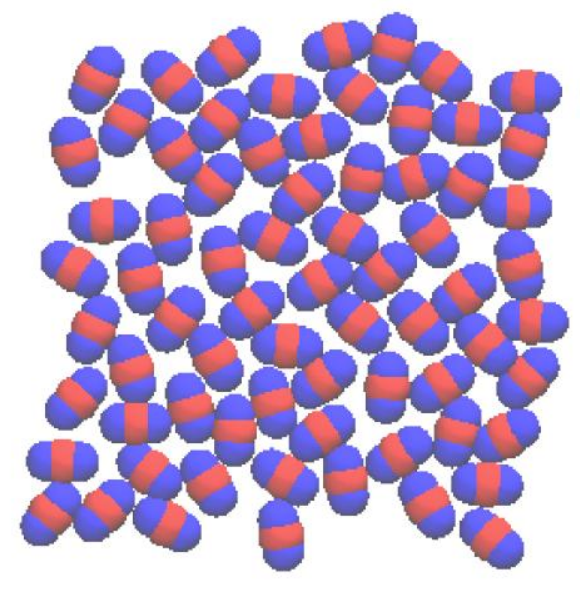

1 st peak

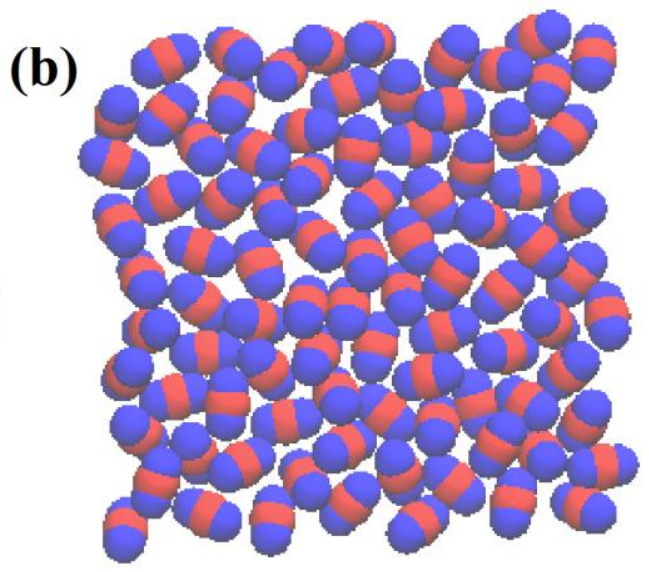

3rd peak

Figure 4. Adsorption stress of $\mathrm{CO}_{2}$ at $293 \mathrm{~K}$ in slit-shaped carbon micropores computed for bulk relative pressures from $10^{-8}$ to 0.995 (a). Maximum adsorption stresses are computed for the $0.28 \mathrm{~nm}$ carbon ultramicropore (1st peak in b). The minimum of the adsorption stress is found in the $0.44 \mathrm{~nm}$ carbon ultramicropore (3rd peak in b). Note the high adsorption stress of nearly $\sim 2.9 \mathrm{GPa}$ close to the saturation in the $0.28 \mathrm{~nm}$ carbon ultramicropore at $293 \mathrm{~K}$. The graphics in this figure were created using the VMD program [72]. 


\subsection{Experimental results and data evaluation}

The experimental $\mathrm{CO}_{2}$ excess adsorption and in-situ strain isotherms for the carbon sample at $293 \mathrm{~K}$ are shown in Figure 5. Analog to the $\mathrm{N}_{2}$ sorption isotherm the $\mathrm{CO}_{2}$ sorption isotherm is of type I and typical for microporous carbons [49,50]. The measured in-situ deformation isotherm is nonmonotonic, which corresponds to other experimental studies reporting adsorption-induced deformation of microporous carbons, see e.g. refs [37,64-66]. For comparison with the simulation results the experimentally determined linear strain $\Delta L / L_{0}$ was converted into the volumetric strain $\varepsilon=3 \Delta L / L_{0}$ as described in section 2.4.2. Initially, the carbon sample contracts up to a relative pressure of $p / p_{0}=0.0028$, followed by a continuous swelling up to $p / p_{0}=0.02$, i.e. the upper limit of the experimentally accessible pressure range. The maximal initial contraction of the studied carbon xerogel sample of approximately $0.01 \mathrm{vol} \%$ is significantly smaller than the maximal expansion of $0.14 \mathrm{vol} \%$. Such non-linear variation of adsorption-induced deformation with relative pressure was predicted by Kowalczyk and co-workers to be a signature of structural heterogeneity of micropores [45].

We applied the models described in sections 2.4.1 (GAE) and 2.4.2 (thermodynamic model) on the excess adsorption and the in-situ strain isotherm, respectively, aiming for the best possible fit of the experimental data sets. The results of the fitting process are also shown in Figure 5. Both, the GAE and the thermodynamic model of adsorption-induced deformation were able to achieve reasonable agreement with their respective isotherm. The pore volume distributions (PVDs) and pore surface area distributions (PSDs) evaluated independently from the gas adsorption and volumetric strain isotherms are compared in Figure 6 and 7. 

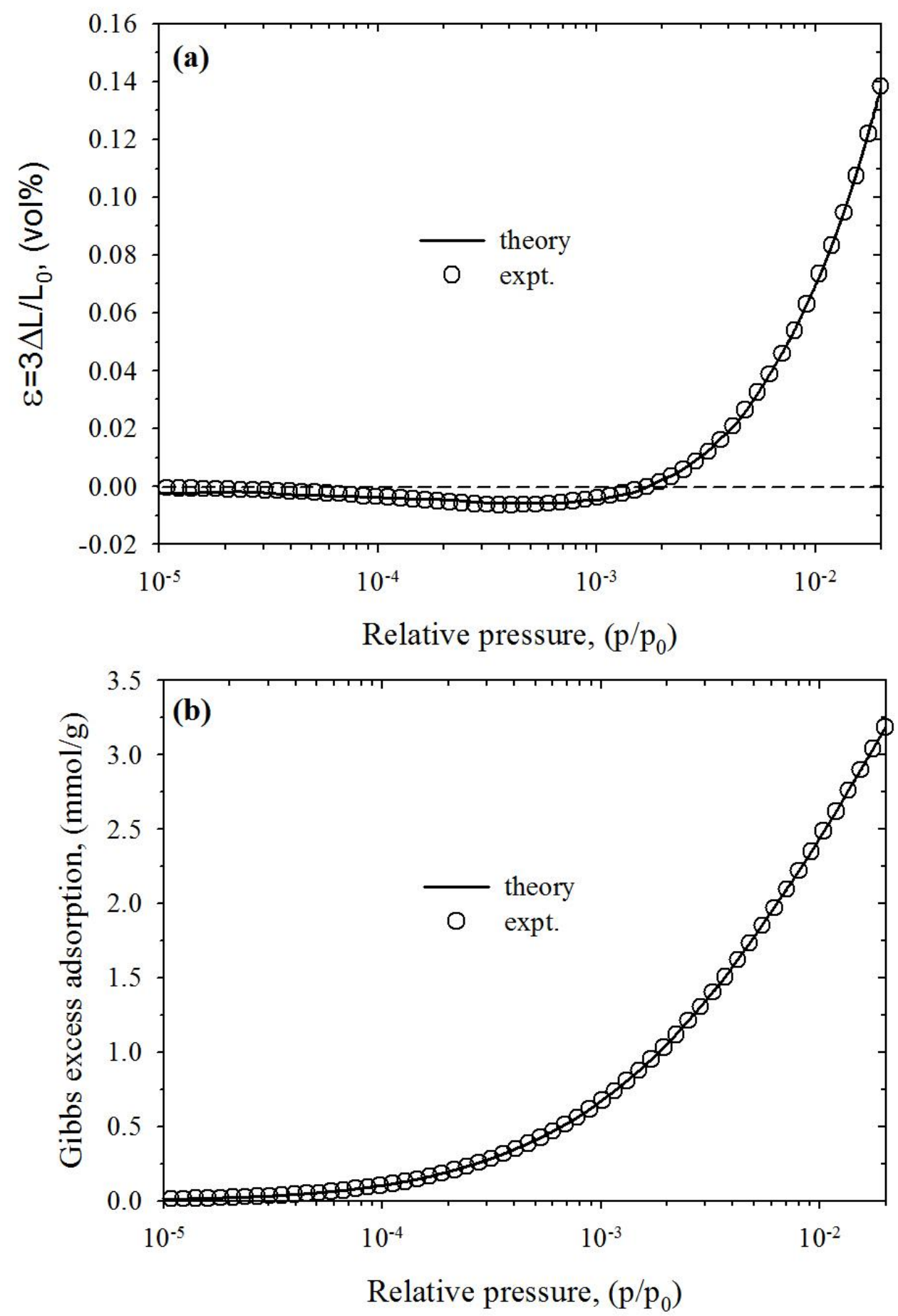

Figure 5. In-situ $\mathrm{CO}_{2}$ strain (a) and excess adsorption isotherm (b) measured at $293 \mathrm{~K}$ (open circles). Theoretical strain isotherm (solid line) is obtained from eq. 4, whereas theoretical $\mathrm{CO}_{2}$ excess adsorption isotherm (solid line) is computed from eq. 1. The respective pore size distributions are shown in Figure 6 and 7. 

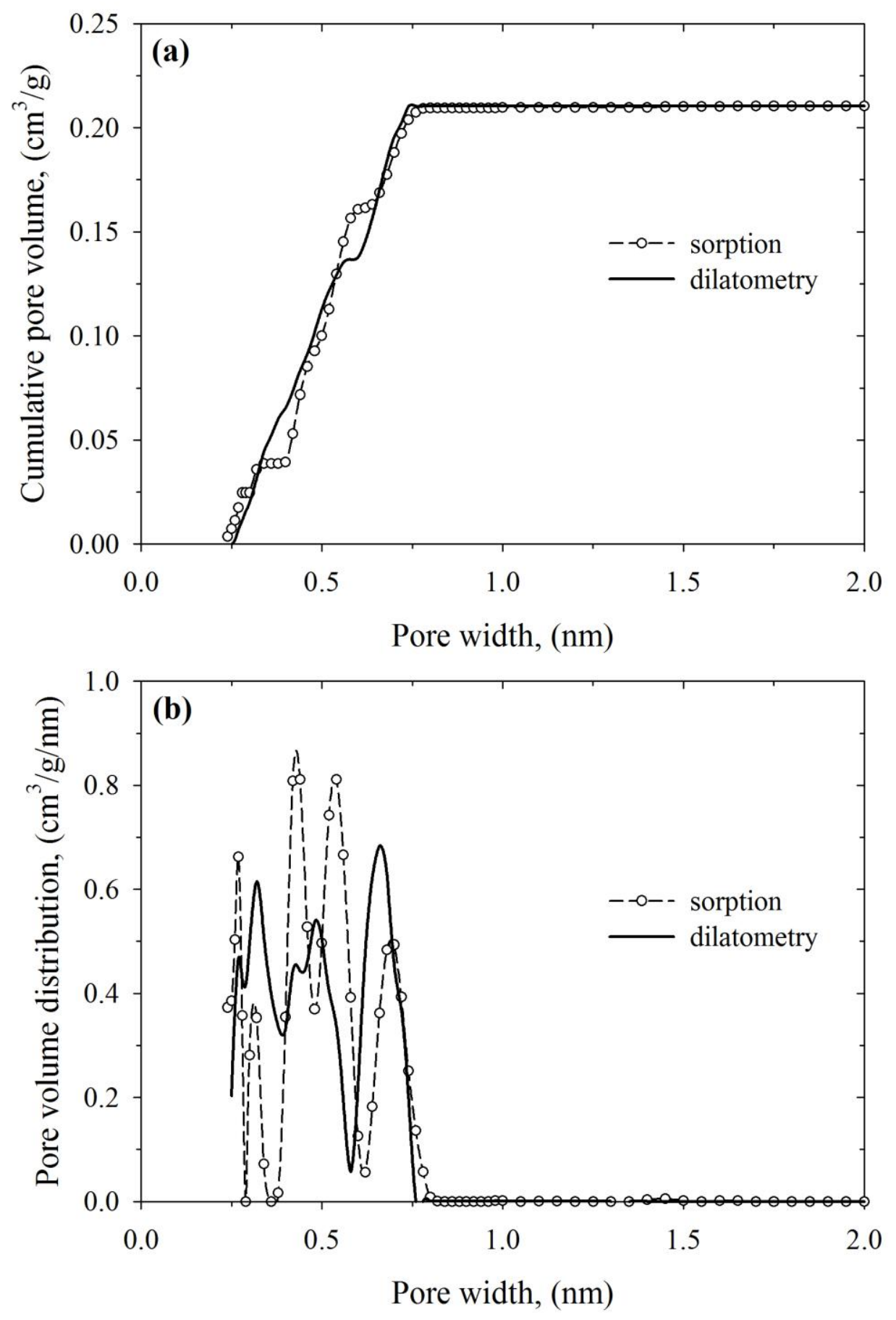

Figure 6. Cumulative (a) and differential (b) micropore volume distributions of carbon xerogel computed from $\mathrm{CO}_{2}$ excess adsorption (sorption) and in-situ strain isotherm at $293 \mathrm{~K}$ (dilatometry). 

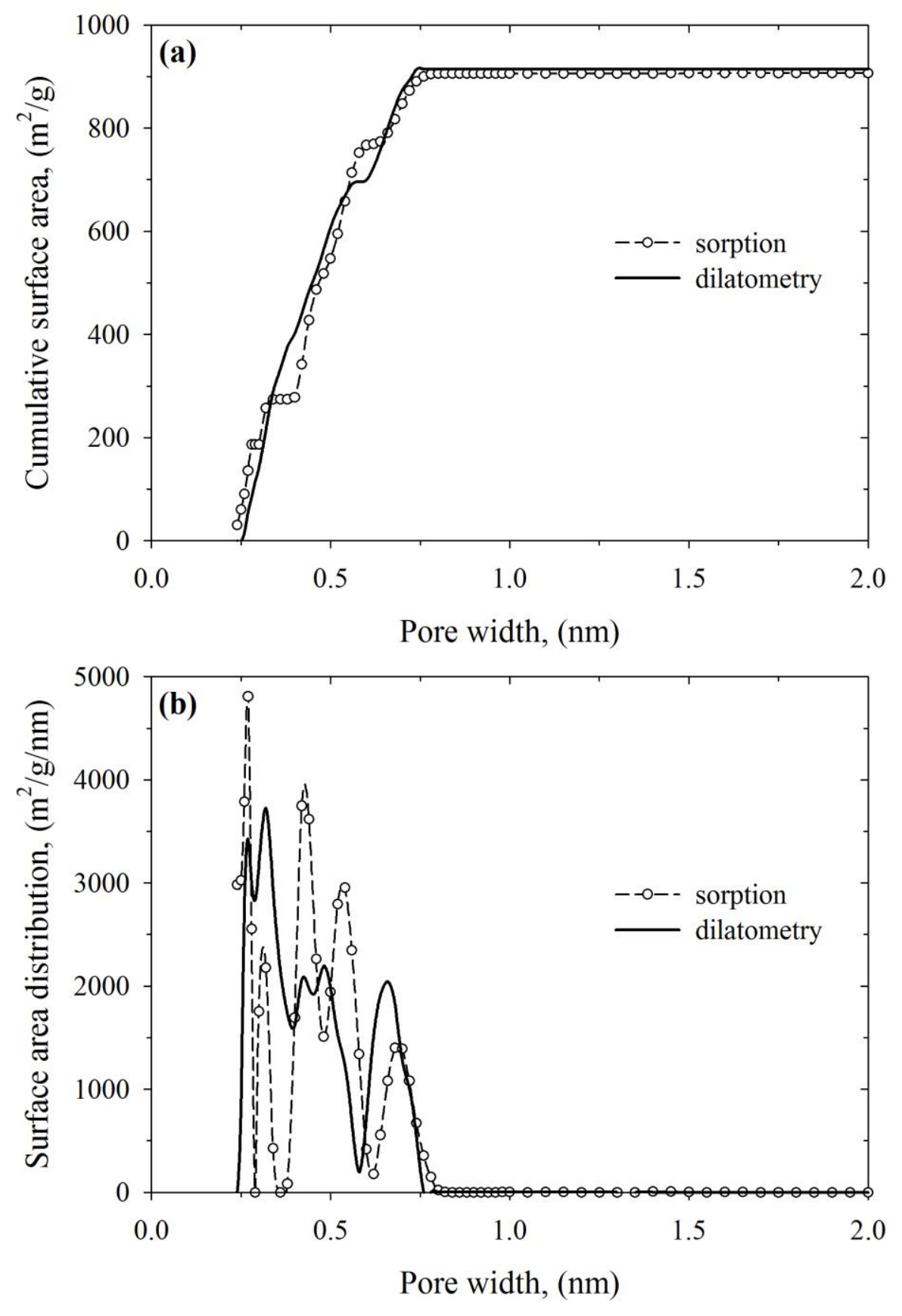

Figure 7. Cumulative (a) and differential (b) micropore surface area distributions of carbon xerogel computed from $\mathrm{CO}_{2}$ excess adsorption (sorption) and in-situ strain isotherm at $293 \mathrm{~K}$ (dilatometry). 
According to both PVDs the carbon xerogel consists mainly of ultramicropores in the range of 0.25 to $0.75 \mathrm{~nm}$. The total specific micropore surface area and volume computed from GAE with the first order Tikhonov regularization constrain are $906 \mathrm{~m}^{2} / \mathrm{g}$ and $0.21 \mathrm{~cm}^{3} / \mathrm{g}$, respectively. The results obtained from GAE using the second order Tikhonov regularization constrain, i.e. $866 \mathrm{~m}^{2} / \mathrm{g}$ and $0.20 \mathrm{~cm}^{3} / \mathrm{g}$, are slightly reduced because the higher degree of smoothing in the approximate solution. From the fitting of the $\mathrm{CO}_{2}$ strain isotherm by the thermodynamic model we get a total specific micropore surface area of $915 \mathrm{~m}^{2} / \mathrm{g}$ and a specific micropore volume of $0.21 \mathrm{~cm}^{3} / \mathrm{g}$. Therefore, we conclude that the values of structural parameters of carbon micropores computed independently from gas adsorption and in-situ dilatometry are consistent.

Independent of the applied approach the differential PVD/PSDs (Fig. 6b and 7b) are not uniform but exhibit spikes suggesting a detailed substructure of the carbon matrix; this effect is more pronounced for the differential distributions derived from the inversion of the GAE than for their counterparts evaluated from the situ strain isotherm. From the experimental point of view a substructure of the carbon matrix appears unphysical, since the micropore structure of the carbon xerogel sample is expected to be entirely disordered [48]. Therefore the spikes of the differential pores size/volume distributions (Fig. $6 \mathrm{~b}$ and $7 \mathrm{~b}$ ) should be taken with reservation. The model of slit pores with smooth walls may be too idealized to reflect the real pore geometry of carbons accurately in the ultramicropore range, where adsorbate density and adsorption stress are determined by molecular packing that is extremely sensitive to pore width and shape. It was shown that the introduction of surface roughness smoothens the pore size dependences of the molecular packing [28]. Consequently the results presented Figures 6 and 7 should be considered as distributions of "effective" sizes of ultramicropores, which give an approximate description of the sample investigated but are not be over-interpreted on the sub-angstrom scale. So generally the application of a more refined carbon model appears desirable, e.g. a 3D reconstruction of the disordered structure [15]. However, despite its simplicity, the slit pore model consistently captures the most important physical mechanisms of the adsorption and the adsorption deformation phenomena. In particular the cumulative pore volume and area distributions derived from the adsorption and strain isotherms (Fig. 6a and 7a) can be smoothened and approximated by one interpolating function resulting in approximately the same overall micropore volume and area. This 
confirms our main conclusion that strain isotherms can be used for pore structure analysis validating or even complementing the conventional methods based on the analysis of adsorption isotherms.

Comparing the structural evaluation of the sample investigated derived from $\mathrm{N}_{2}$ and $\mathrm{CO}_{2}$ sorption analysis we find that all PVDs are overlapping in the range of pore widths between 0.5 and $0.6 \mathrm{~nm}$ (compare Figures 1d and 7), but the PVDs computed from $\mathrm{CO}_{2}$ data are significantly broader and more detailed than the ones derived from the $\mathrm{N}_{2}$ sorption isotherm. As was pointed out in ref. [22] micropore analysis from $\mathrm{N}_{2}$ sorption data taken at cryogenic temperatures is limited to pore widths larger than approximately $0.5 \mathrm{~nm}$ because of the experimental pressure resolution of currently used instruments. So generally we expect PVDs/PSDs evaluated from $\mathrm{CO}_{2}$ data to be more reliable with respect to narrow ultramicropores. Considering the total specific pore volume and the total specific surface area, we find that $\mathrm{CO}_{2}$ results yield more surface area but less pore volume than the DFT analysis of the $\mathrm{N}_{2}$ sorption isotherm. While the increased surface area is related to the smaller pore sizes of the $\mathrm{CO}_{2}$ PSDs (see Figure 7), the reduced pore volume can be explained by the upper experimental limit for the relative pressure of 0.02 at $293 \mathrm{~K}$. Micropores larger than approximately $0.8 \mathrm{~nm}$ exhibit significant adsorption only for relative gas pressures above 0.02 and therefore cannot be resolved by the analysis of the $\mathrm{CO}_{2}$ adsorption isotherm (see Figures 3,6 and 7). The cumulative specific pore volume at $0.8 \mathrm{~nm}$ derived from $\mathrm{N}_{2}$ sorption is $0.22 \mathrm{~cm}^{3} / \mathrm{g}$ for NLDFT and $0.23 \mathrm{~cm}^{3} / \mathrm{g}$ for QSDFT, both being in reasonable agreement with the results of the $\mathrm{CO}_{2}$ data evaluation.

The proposed method of analysis of the in-situ adsorption dilatometry data provides an important information about the sample mechanical properties. Good agreement between the pore size distributions derived by the GAE and the thermodynamic model of sorption-induced deformation implies that the sample bulk modulus $K$ in Eq. 4 can be considered a constant, independent of the micropore deformation, and the application of Hook's law is justified. It is worth noting that the recent simulations performed by Mouhat et al. [67] predicted possible changes of the mechanical stiffness during adsorption that are not revealed for the microporous carbon considered here. From the fitting of the deformation isotherm by the thermodynamic model we get $K=3.1 \mathrm{GPa}$, which according to the model corresponds to the effective mechanical stiffness of the particles seen in Figure 1a. 
Since no direct measurements of the mechanical properties of individual particles are feasible, we can only estimate respective values from literature: employing the correlation of carbon xerogel stiffness and macroscopic density derived by Gross and co-workers [68] we extrapolated $K$ to be approximately $15 \mathrm{GPa}$. This value is remarkably close to bulk moduli measured for glassy carbon [69-71], a purely microporous disordered carbon material, which is comparable to the particles within the sample investigated in terms of synthesis, structure and density. Therefore we conclude that the bulk modulus derived from the application of the thermodynamic model is of the correct order of magnitude but somewhat lower than expected.

Given the good quantitative description of the experimental data by the proposed theoretical we extrapolated the $\mathrm{CO}_{2}$ excess adsorption and the accompanying strain isotherms at $293 \mathrm{~K}$ into the relative pressure range above 0.02 , which was not accessible in the experiment (see Figure 8). From this calculation we predict that the elastic deformation of the carbon xerogel induced by $\mathrm{CO}_{2}$ molecules linearly increases with the logarithm of relative pressure above $p / p_{0}=0.05$, showing the maximum expansion of the studied carbon sample of 1.67 vol\% at the saturation. The $\mathrm{CO}_{2}$ excess adsorption isotherm extrapolated from PVD and the GAE is nonmonotonic. Excess adsorption increases for relative pressures up to 0.39, indicating strong adsorption of $\mathrm{CO}_{2}$ in ultramicropores. The maximum value of $\mathrm{CO}_{2}$ excess adsorption of $4.65 \mathrm{mmol} / \mathrm{g}$ on the carbon sample is theoretically predicted for $p / p_{0}=$ 0.39. At higher relative pressures, the $\mathrm{CO}_{2}$ excess adsorption continuously decreases because the restricted packing of $\mathrm{CO}_{2}$ molecules in carbon ultramicropores. 

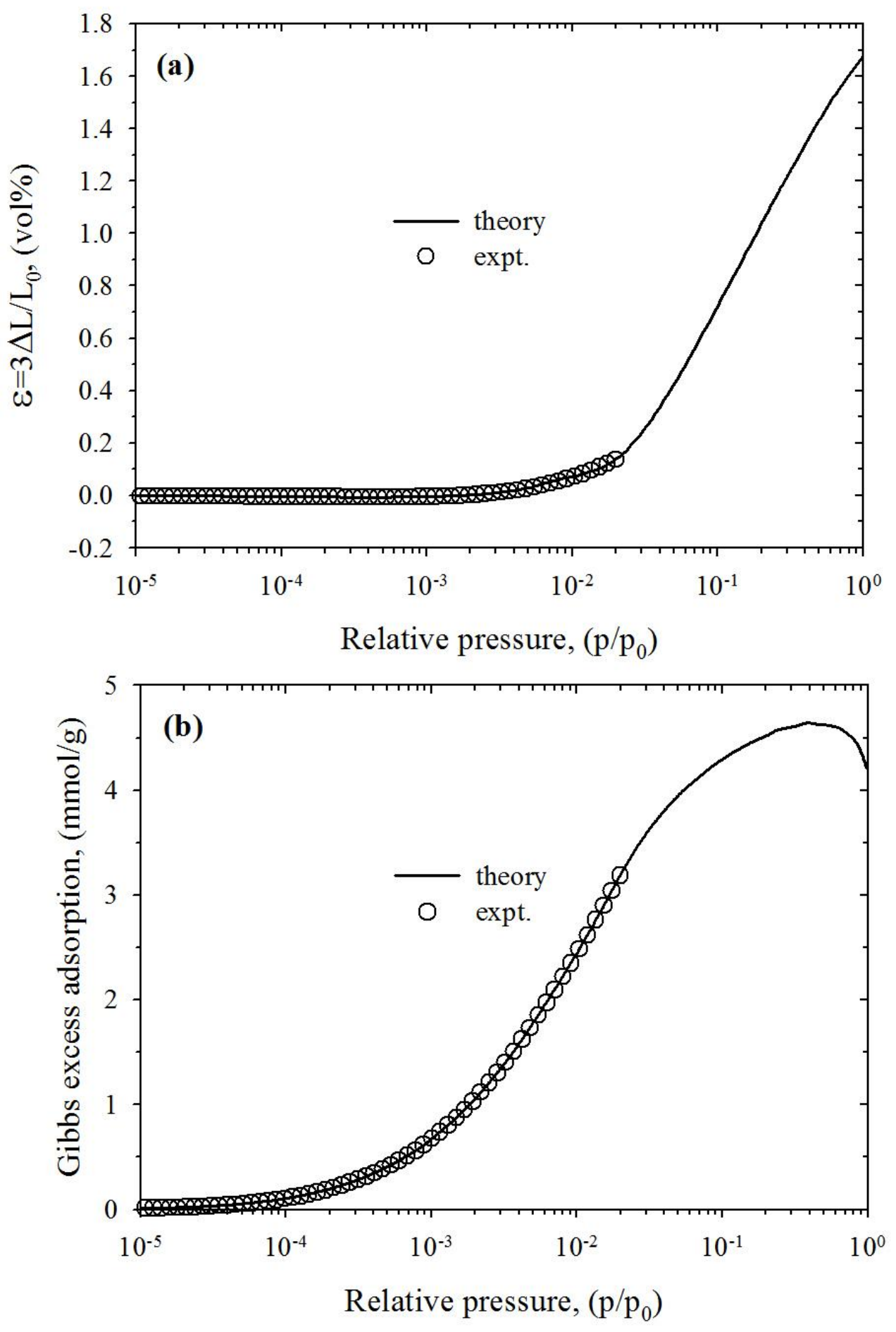

Figure 8. Extrapolation of experimental $\mathrm{CO}_{2}$ excess and in-situ strain isotherms (expt.) measured up to $p / p_{0}=0.02$ to saturation at $293 \mathrm{~K}$ (theory). Note that carbon xerogel sample expands up to $1.67 \mathrm{vol} \%$ at saturation. The extrapolated $\mathrm{CO}_{2}$ excess adsorption isotherm is non-monotonic, with the maximum excess value of $\mathrm{CO}_{2}$ adsorption of $4.65 \mathrm{mmol} / \mathrm{g}$ at $p / p_{0}=0.39$. 


\section{Conclusions}

In the current work we presented the first attempt towards characterization of microporo-elastic properties of disordered and heterogeneous carbon materials from the $\mathrm{CO}_{2}$ gas adsorption measurement accompanied with in-situ dilatometry at $293 \mathrm{~K}$. We applied the generalized integral equation and the thermodynamic model of adsorption-induced deformation of microporous materials to compute the structural properties of the studied carbon sample from the adsorption and in-situ strain isotherms, respectively. Both theoretical methods produced consistent results with respect to the distribution of micropore surface area and volume as well as the total specific micropore surface area and volume. Notably, the pore volume and area distributions evaluated from the strain isotherm are somehow smoother than their counterparts computed from the $\mathrm{CO}_{2}$ excess adsorption isotherm. For the sample investigated the total specific surface area of approximately $900 \mathrm{~m}^{2} / \mathrm{g}$ and the total specific micropore volume of $0.21 \mathrm{~cm}^{3} / \mathrm{g}$ are distributed over the range of ultramicropores between 0.25 and $0.75 \mathrm{~nm}$. Additionally, we evaluated the bulk modulus for the microporous matrix of $3.1 \mathrm{GPa}$ from the strain isotherm, which is of the same order of magnitude as expected from the extrapolation of sound velocity measurement results. Extrapolation of the adsorption and strain isotherms to higher pressures than accessible in experiment predicts that the carbon sample monotonically expands up to $1.67 \mathrm{vol} \%$ at saturation. This finding of the extension of the effects of the micropore filling on the sample deformation at high pressures may have important implications for the interpretation of the adsorption-induced deformation in the micromesoporous materials of hierarchical structure, such as coal seams during geological sequestration of carbon dioxide and secondary methane recovery [73,74].

\section{Acknowledgements}

P.K. acknowledges partial support from the startup grant (Nanopore controlled synthetic carbons for interfacial separations and catalysis) awarded from the School of Engineering and Information Technology, Murdoch University. A.P.T. and P.A.G. acknowledge the use of the computer cluster at Poznan Supercomputing and Networking Centre (Poznan, Poland) as well as the Information and Communication Technology Centre of the Nicolaus Copernicus University (Torun, Poland). P.K. 
acknowledges Prof. Katsumi Kaneko (Shinshu University, Japan) for fruitful comments about the current work. A.V.N. acknowledges support from the Rutgers NSF ERC on Structured Organic Particulate Systems.

\section{References}

[1] M. Inagaki, K. Feiyu, Carbon Materials Science and Engineering - From Fundamentals to Applications, Beijing: Tsinghua University Press, 2006.

[2] S. J. Gregg, K. S. W. Sing, Adsorption, Surface Area and Porosity, London: Academic Press, 1982.

[3] P. Kowalczyk, P. A. Gauden, A. P. Terzyk, A. V. Neimark, Screening of carbonaceous materials for capture of nerve agents, Physical Chemistry Chemical Physics 15 (2012) 291-298.

[4] J. Chmiola, C. Largeot, P.-L. Taberna, P. Simon, Y. Gogotsi, Monolithic carbidederived carbon films for micro-supercapacitors, Science 328 (2010) 480-483.

[5] M. E. Casco, M. Nartínez-Escandell, E. Gadea-Ramos, K. Kaneko, J. SilvestreAlbero, F. Rodríguez-Reinoso, High-pressure methane storage in porous materials: are carbon materials in the pole position ?, Chem. Mater. 27 (2015) 959-964.

[6] K. Hyunsig, T. Kim, K. Hata, K. Ideta, T. Ohba, H. Kanoh, S. Yoon, J. Miyawaki, Influence of surface functionalities on ethanol adsorption characteristics in activated carbons for adsorption heat pumps, Appl. Therm. Eng. 72 (2014) 160-165.

[7] P. Kowalczyk, H. Tanaka, R. Holyst, K. Kaneko, T. Ohmori, J. Miyamoto, Storage of hydrogen at $303 \mathrm{~K}$ in graphite slitlike pores from Grand Canonical Monte Carlo simulation, J. Phys. Chem. B 109 (2005) 17174-17183.

[8] R. Ch. Bansal, M. Goyal, Activated Carbon Adsorption, Boca Raton: CRC Press, 2005.

[9] K. Kaneko, Determination of pore size and pore size distribution. 1. Adsorbents and catalysts, J. Membrane Sci. 96 (1994) 59-89.

[10] P.I. Ravikovitch, A. Vishnyakov, R. Russo, A. V. Neimark, Unified approach to 
pore size characterization of microporous carbonaceous materials from $\mathrm{N}_{2}$, Ar, and $\mathrm{CO}_{2}$ adsorption isotherms, Langmuir 16 (2000) 2311-2320.

[11] A. Burian, A. Ratuszna, J. C. Dore, Radial distribution function analysis of the structure of activated carbons, Carbon 36 (1998) 1613-1621.

[12] S. K. Jain, R. J.-M. Pellenq, J. P. Pikunic, K. E. Gubbins, Molecular modelling of porous carbons using hybrid reverse Monte Carlo method, Langmuir 22 (2006) 99429948.

[13] J. C. Palmer, J. K Brennan, M. M. Hurley, A. Balboa, K. E. Gubbins, Detailed structural model for activated carbons from molecular simulation, Carbon 47 (2009) 2904-2913.

[14] T. X. Nguyen, N. Cohaut, J.-S. Bae, S. K. Bhatia, New method for atomistic modelling of the microstructure of activated carbons using hybrid reverse Monte Carlo simulation, Langmuir 24 (2008) 7912-7922.

[15] P. Kowalczyk, A. P. Terzyk, P. A. Gauden, S. Furmaniak, M. Wiśniewski, A. Burian, L. Hawelek, K. Kaneko, A. V. Neimark, Carbon molecular sieves: reconstruction of atomistic structural models with experimental constrains, J. Phys. Chem. C 118 (2014) 12996-13007.

[16] S. H. Madani, Ch. Hu, A. Silvestre-Albero, M. J. Biggs, F. Rodríguez-Reinoso, P. Pendleton, Pore size distributions derived from adsorption isotherms, immersion calorimetry, and isosteric heats: A comparative study, Carbon 96 (2016) 1106-1113.

[17] H. Marsh, F. Rodríguez-Reinoso, Activated Carbon, London: Elsevier Ltd., 2006.

[18] M. M. Dubinin, Micropore structures of charcoal adsorbents. 1. A general characterization of micro- and supermicropores in the fissure model, Bull. Acad. Sci. USSR 28 (1979) 1560-1564.

[19] M. Thommes, K. Cychosz, A. V. Neimark, Advanced physical adsorption characterization of nanoporous carbons, in Novel carbon adsorbents, J. M. D. Tascon (Ed.), London: Elsevier Ltd., 2012, pp. 107-145.

[20] P. Kowalczyk, A. P. Terzyk, P. A. Gauden, R. Leboda, E. Szmechting-Gauden, G. Rychlicki, Z. Ryu, H. Rong, Estimation of the pore size distribution from nitrogen adsorption isotherm. The comparison of density functional theory and the method of Do and co-workers, Carbon 41 (2003) 1113-1125.

[21] Ch. Lastoskie, K. E. Gubbins, N. Quirke, Pore size distribution analysis of 
microporous carbons: a density functional theory approach, J. Phys. Chem. 97 (1993) 4786-4796.

[22] P.I. Ravikovitch, A. Vishnyakov, R. Russo, A. V. Neimark, Unified approach to pore size characterization of microporous carbonaceous materials from $\mathrm{N}_{2}$, Ar, and $\mathrm{CO}_{2}$ adsorption isotherms, Langmuir 16 (2000) 2311-2320.

[23] D. M. Davies, N. A. Seaton, V. S. Vassiliadis, Calculation of pore size distribution of activated carbons from adsorption isotherms, Langmuir 15 (1999) 8235-8245.

[24] P. A. Gauden, P. Kowalczyk, A. P. Terzyk, Toward solving the unstable linear Fredholm equation of the first kind: a new procedure called the adsorption stochastic algorithm (ASA) and its properties, Langmuir 19 (2003) 4253-4268.

[25] J. Jagiello, M. Thommes, Comparison of DFT characterization methods based on $\mathrm{N}_{2}, \mathrm{Ar}, \mathrm{CO}_{2}$, and $\mathrm{H}_{2}$ adsorption applied to carbons with various pore size distributions, Carbon 42 (2004) 1227-1232.

[26] E. A. Ustinov, D. D. Do, High-pressure adsorption of supercritical gases on activated carbons: and improved approached based on the density functional theory and the Bender equation of state, Langmuir 19 (2003) 8349-8357.

[27] T. X. Nguyen, S. K. Bhatia, D. Nicholson, Prediction of high-pressure adsorption equilibrium of supercritical gases using density functional theory, Langmuir 21 (2005) 3187-3197.

[28] A. V. Neimark, Y. Lin, P. I. Ravikovitch, M. Thommes, Quenched solid density functional theory and pore size analysis of micro-mesoporous carbons, Carbon 47 (2009) 1617-1628.

[29] V. Yu. Gusev, J. A. O'Brien, N. A. Seaton, A self-consistent method for characterization of activated carbons using supercritical adsorption and Grand Canonical Monte Carlo simulations, Langmuir 13 (1997) 2815-2821.

[30] P. Kowalczyk, H. Tanaka, K. Kaneko, A. P. Terzyk, D. D. Do, Grand Canonical Monte Carlo simulation study of methane adsorption at an open graphite surface and in slitlike carbon pores at $273 \mathrm{~K}$, Langmuir 21 (2005) 5639-5646.

[31] S. Furmaniak, A. P. Terzyk, M. Jaroniec, P. A. Gauden, Argon adsorption in channel-like mesoporous carbons at $77 \mathrm{~K}$ : Grand Canonical Monte Carlo simulations and pore size analysis, Microporous and Mesoporous Materials 116 (2008) 665-669. [32] S. Samios, A. K. Stubos, N. K. Kanellopoulos, R. F. Cracknell, G. K. 
Papadopoulos, D. Nicholson, Determination of micropore size distribution from Grand Canonical Monte Carlo simulations and experimental $\mathrm{CO}_{2}$ isotherm data, Langmuir 13 (1997), 2795-2802.

[33] P. H. Hansen, Rank-deficient and discrete ill-posed problems, Philadelphia: SIAM 1992.

[34] A. N. Tikhonov, A. V. Goncharsky, V. V. Stepanov, A. G. Yagola, Numerical Methods for the Solution of Ill-Posed Problems, London: Kluwer Academic Publishers, 1995.

[35] D. H. Bangham, N. Fakhoury, The expansion of charcoal accommodating sorption of gases and vapours, Nature 3 (1928) 681-682.

[36] A. V. Tvardovskiy, Sorption Deformation, Amsterdam: Elsevier Ltd., 2006.

[37] C. Balzer, S. Braxmeier, A. V. Neimark, G. Reichenauer, Deformation of microporous carbon during adsorption of nitrogen, argon, carbon dioxide, and water studied by in situ dilatometry, Langmuir 31 (2015) 12512-12519.

[38] C. Balzer, T. Widhage, S. Braxmeier, G. Reichenauer, J. P. Oliver, Deformation of porous carbons upon adsorption, Langmuir 27 (2011) 2553-2560.

[39] P. I. Ravikovitch, A. V. Neimark, Density functional theory model of adsorption deformation, Langmuir 22 (2006) 10864-10868.

[40] G. Yu. Gor, A. V. Neimark, Adsorption-induced deformation of mesoporous solids, Langmuir 26 (2010) 13021-13027.

[41] K. Yang, X. Lu, Y. Lin, A. V. Neimark, Deformation of coal induced by methane adsorption at geological conditions, Energy \& Fuels 24 (2010) 5955-5964.

[42] P. Kowalczyk, S. Furmaniak, P. A. Gauden, A. P. Terzyk, Methane-induced deformation of porous carbons: from normal to high-pressure operating conditions, J. Phys. Chem. C 116 (2012) 1740-1747.

[43] P. Kowalczyk, S. Furmaniak, P. A. Gauden, A. P. Terzyk, Carbon dioxide adsorption-induced deformation of microporous carbons, J. Phys. Chem. C 114 (2010) 5126-5133.

[44] P. Kowalczyk, A. Ciach, A. P. Terzyk, P. A. Gauden, S. Furmaniak, Effects of critical fluctuations on adsorption-induced deformation of microporous carbons, $\mathrm{J}$. Phys. Chem. C 119 (2015) 6111-6120.

[45] P. Kowalczyk, A. Ciach, A. V. Neimark, Adsorption-induced deformation of microporous carbons: pore size distribution effect, Langmuir 24 (2008) 6604-6608. 
[46] R.W. Pekala, F. M. Kong, A synthetic route to organic aerogels - mechanism, structure, and properties. J. Phys.-Paris 50 (C-4) (1989) C433-C440.

[47] M. Wiener, G. Reichenauer, T. Scherb, J. Fricke, Accelerating the synthesis of carbon aerogel precursors, J. Non-Cryst. Solids, 350 (2004) 126-130.

[48] M. Wiener, G. Reichenauer, Microstructure of porous carbons derived from phenolic resin - impact of annealing at temperatures up to $2000{ }^{\circ} \mathrm{C}$ analyzed by complementary characterization methods, Micropor. Mesopor. Mat. 203 (2015) 116122.

[49] K. S. W. Sing, D. H. Everett, R. A. W. Haul, L. Moscou, R. A. Pierotti, J. Rouquérol, T. Siemieniewska, Reporting physisorption data for gas/solid systems with special reference to the determination of surface area and porosity, Pure Appl. Chem. 57 (1985) 603-619.

[50] M. Thommes, K. Kaneko, A. V. Neimark, J. P. Olivier, F. Rodriguez-Reinoso, J. Rouquérol, K. S. W. Sing, Physisorption of gases, with special reference to the evaluation of surface area and pore size distribution (IUPAC Technical Report), Pure Appl. Chem. 87 (2015) 1051-1069.

[51] B. C. Lippens, J. H. de Boer, Studies on pore systems in catalysts: V. The $t$ method, J. Catal. 4 (1965) 319-323.

[52] R. W. Magee, Evaluation of the external surface area of carbon black by nitrogen adsorption, Rubber Chem. Technol. 68 (1994) 590-600.

[53] R. W. Pekala, C. T. Alviso, Carbon aerogels and xerogels, Mater. Res. Soc. Symp. 270 (1992) 3-14.

[54] C. Balzer, R. Morak, M. Erko, C. Triantafillidis, N. Hüsing, G. Reichenauer, O. Paris, Relationship Between Pore Structure and Sorption-Induced Deformation in Hierarchical Silica-Based Monoliths. Zeitschrift Fur Physikalische ChemieInternational Journal of Research in Physical Chemistry \& Chemical Physics, 229 (2015) 1189-1209.

[55] A. V. Tvardovski, A. A. Fomkin, Y. I. Tarasevich, I. G. Polyakova, V. V. Serpinski, I. M. Guseva, I. M. Investigation of Cation-Substituted Vermiculite Deformation Upon Water Vapor Sorption, J. Colloid Interf. Sci. 164 (1994) 114-118.

[56] G. Reichenauer, G. W. Scherer, Nitrogen adsorption in compliant materials, J. Non-Cryst. Solids 277 (2000) 162-172.

[57] E. W. Lemmon, M. O. McLinden, D. G. Friend, Thermophysical Properties of 
Fluid Systems, Gaithersburg: National Institute of Standards and Technology, 2015.

[58] T. X. Nguyen, Characterization of nanoporous carbons, Brisbane: The University of Queensland, 2006.

[59] P. Kowalczyk, S. Furmaniak, P. A. Gauden, A. P. Terzyk, Optimal single-walled carbon nanotube vessels for short-term reversible storage of carbon dioxide at ambient temperatures, J. Phys. Chem. C 114 (2010) 21465-21473.

[60] W. A. Steele, The physical interaction of gases with crystalline solids: I. Gassolid energies and properties of isolated adsorbed atoms, Surf. Sci. 36 (1973) 317 352.

[61] D. Nicholson, N. G. Parsonage, Computer Simulation and Statistical Mechanics of Adsorption, London: Academic Press, 1982.

[62] P. Kowalczyk, J. He, P. A. Gauden, S. Furmaniak, A. P. Terzyk, To the pore and through the pore: thermodynamics and kinetics of helium in exotic cubic carbon polymorphs, Phys. Chem. Chem. Phys. 15 (2013) 17366-17373.

[63] P. B. Balbuena, D. Berry, K. E. Gubbins, Solvation pressures for simple fluids in micropores, J. Phys. Chem. 97 (1993) 937-943.

[64] R. S. Haines, R. McIntosh, Length change of carbon rods caused by adsorption of vapors, J. Chem. Phys. 15 (1947) 28-38.

[65] J. R. Dacey, M. J. B. Evans, Volume changes in saran charcoal caused by the adsorption of water, methanol and benzene vapours, Carbon 9 (1971) 579-585.

[66] V. Y. Yakovlev, A. A. Fomkin, A. V. Tvardovski, Adsorption and deformation phenomena at the interaction of $\mathrm{CO}_{2}$ and a microporous carbon adsorbent, J. Colloid Interf. Sci. 268 (2003) 33-36.

[67] F. Mouhat, D. Bousque, A. Boutin, L. B. du Bourg, F.-X. Coudert, A. H. Fuchs, Softening upon adsorption in microporous materials: a counterintuitive mechanical response, J. Phys. Chem. Lett. 6 (2015) 4265-4269.

[68] J. Gross, G. Reichenauer, J. Fricke, Mechanical-properties of $\mathrm{SiO}_{2}$ aerogels, J. Phys. D Appl. Phys. 21 (1988) 1447-1451.

[69] M. K. Halpin, G. M. Jenkins, Interaction of glassy carbon with alkali metal vapours, Proc. Roy. Soc. Lond. A 313 (1969) 421-431.

[70] J. A. Katerberg, A. C. Anderson, Low-temperature specific-heat, thermalconductivity, and ultrasonic velocity of glassy carbons, J. Low Temp. Phys. 30 (1978) 739-745. 
[71] C. Garion, Mechanical properties for reliability analysis of structures in glassy carbon. World Journal of Mechanics 4 (2014) 79-89.

[72] W. Humphrey, A. Dalke, K. Schulten, VMD - Visual Molecular Dynamics J. Molec. Graphics 14.1. (1996) 33-38.

[73] K. Yang, X. Lu, Y. Lin, A.V. Neimark, Deformation of coal induced by methane adsorption at geological conditions, Energy Fuel 24 (2010) 5955-5964.

[74] K. Yang, X. Lu, Y. Lin, A.V. Neimark, Effects of coal deformation upon $\mathrm{CO}_{2}$ adsorption and sequestration, J. Geophys. Res.-Solid Earth 116 (2011) B08212. 